\title{
A era da testemunha: uma história do presente ${ }^{1}$
}

Igor SACRAMENTO ${ }^{2}$

\section{Resumo:}

A cultura contemporânea está fortemente marcada pelo alargamento do espaço biográfico. É cada vez mais crescente o processo de articulação dessas narrativas biográficas à mídia. $\mathrm{O}$ objetivo deste artigo é abordar um processo de mutação história naquilo que Annette Wieviorka chamou de "a era da testemunha", quando tratou dos testemunhos sobre o Holocausto. O que se vive atualmente, especialmente no contexto da presença da televisão e da internet na vida social e pelo rearranjo da subjetividade a partir da moral do espetáculo, é crescente presença do discurso terapêutico na construção e na exposição de experiências cotidianas de sofrimento.

Palavras-chave:

Testemunho. Sofrimento. Mídia. Biografia. Subjetividade.

\section{The witness era: a history of the present}

\begin{abstract}
:
Contemporary culture is strongly marked by the widening of the biographical space. The process of articulating these biographical narratives to the media is increasingly increasing. The purpose of this article is to treat a process of mutation history in what Annette Wieviorka called "the era of the witness" when she dealt with the testimonies about the Holocaust. What is currently happening, especially in the context of the presence of television and the internet in social life and the rearrangement of subjectivity based on the morality of the spectacle, is a growing presence of therapeutic discourse in the construction and exposition of everyday experiences of suffering.
\end{abstract}

Keywords:

Testimony. Suffering. Media. Biography. Subjectivity.

\section{La era del testigo: una historia del regalo}

\section{Resumen:}

La cultura contemporánea está fuertemente marcada por la ampliación del espacio biográfico. El proceso de articular estas narraciones biográficas a los medios de comunicación aumenta cada vez más. El propósito de este artículo es tratar un proceso de historia de mutaciones en lo que Annette Wieviorka llamó "la era del testimonio" cuando trató los testimonios sobre el Holocausto. Lo que está ocurriendo actualmente, especialmente en el contexto de la presencia de la televisión y de Internet en la vida social y la reordenación de la subjetividad basada en la moralidad del espectáculo, es una presencia creciente del discurso terapéutico en la construcción y exposición de experiencias cotidianas de sufrimiento.

Palabras clave:

Testimonio. Sufrimiento. Medios de comunicación. Biografía. Subjetividad.

\section{Introdução}

Narrar a vida, não apenas as vidas de homens e mulheres famosos, mas as vidas de pessoas comuns, coloca em jogo o valor de testemunho que lança uma nova luz sobre as experiências do ordinário na contemporaneidade. É preciso saber, no entanto, o

\footnotetext{
${ }^{1}$ Artigo baseado na comunicação apresentada na mesa "Historicidade dos processos comunicacionais" do XI Encontro Nacional de História da Mídia (Alcar, 2017).

${ }^{2}$ Doutor em Comunicação e Cultura (ECO/UFRJ), pesquisador do Laboratório de Pesquisa em Comunicação e Saúde (Laces/Icict/Fiocruz) e professor dos programas de pós-graduação em Comunicação e Cultura (PPGCOM/UFRJ) e Informação e Comunicação em Saúde (PPGCIS/Fiocruz).
} 
que está presente na vida cotidiana que nos leva a valorizar imensamente o biográfico. Como explica Leonor Arfuch (2010), o surgimento de narrativas do eu no mundo contemporâneo delineia um espaço biográfico atravessado pela intencionalidade de captar as experiências que deixaram um rastro, uma marca, uma lembrança.

O espaço biográfico designa não apenas um reservatório de gêneros canônicos, mas, o que é mais importante, um horizonte de análise do que pode ser lido como um sintoma cultural e político que caracteriza o nosso presente. O objetivo de analisar o espaço biográfico busca problematizar a condição de subjetividade contemporânea que se abre para o registro e para a publicização por meio da mídia do relato em primeira pessoa, daquele que dá testemunho, encarregando-se da valorização e da exposição da experiência individual e coletiva em meio às condições mutáveis do presente histórico. Como observa a autora (2010), trata-se de um contexto em que surge uma intimidade pública, expressa em outros tipos de educação sentimental, marcada pela moral do espetáculo. Sendo assim, o relato de experiências de relações de casal, de amor e amizade, estilos de vida e violências assumem um valor testemunhal.

O objetivo deste artigo é tratar de um processo de mutação história naquilo que Annette Wieviorka (1998) chamou de "a era da testemunha", quando abordou os testemunhos sobre o Holocausto. O que se vive atualmente, especialmente no contexto da presença da televisão e da internet na vida social e pelo rearranjo da subjetividade a partir da moral do espetáculo, é uma passagem do "grande testemunho" para o "pequeno testemunho", de um relato sobre acontecimentos relacionados a processos de sistemática violência estatal contra determinados grupos sociais à exposição de experiências cotidianas de sofrimento.

Procuro, com isso, fazer uma reflexão sobre a história do presente. Jean-Pierre Rioux define esse campo historiográfico da seguinte forma: “ $[\mathrm{u}] \mathrm{m}$ vibrato do inacabado que anima todo um passado, um presente aliviado de seu autismo, uma inteligibilidade perseguida fora de alamedas percorridas, é um pouco isto , a História do Presente" (RIOUX, 1999, p. 50). AgnèsChauveau e Philippe Tétart (1999, p. 15) comentam que esse campo se ampara no pressuposto de que a histórianão é apenas o estudo do passado, mas, também, "com um menor recuo e métodos particulares, o estudo do presente". Segundo os autores, algumas dinâmicas sociais estão associadas a esse campo a partir de meados do século XX: a complexificação dos meios de comunicação e de sua articulação com a vida social, a força dos engajamentos segundo políticas de 
identidade (gênero, raça, classe, faixa etária, geração), a elevação do nível educacional, transformações no sistema de produção capitalista e os traumas associados a guerras, conflitos, genocídios, processos de colonização/descolonização, ditaduras. Ao tratar das reconfigurações do testemunho e da testemunha a partir de uma história do presente, busco neste artigo especificar tanto regularidades quanto descontinuidades nas relações entre memória, trauma e subjetividade.

\section{A era da testemunha e os testemunhos sobre o Holocausto}

Especialista na história do genocídio judeu na Segunda Guerra Mundial e na construção da memória sobre o evento, Annette Wieviorka desenvolve em seu livro, L'èredutémoin, a relação entre testemunho e história, distinguindo três fases na história do testemunho. Nos primeiros anos do pós-guerra, as testemunhas queriam lembrar o que aconteceu, mas quase não foram ouvidas. Contrariamente à ideia de que os sobreviventes não falaram, existe, apenas na França, uma produção escrita considerável de histórias autobiográficas de sobreviventes, imediatamente após o retorno. No entanto, poucos sobreviventes conseguiram conversar com seus entes queridos sobre o que tinham experimentado, então recuaram para si mesmos.

A segunda era, mais literária, é a das histórias publicadas cerca de dez anos após o retorno. Sobrepostos a essas obras literárias estão os testemunhos que passaram a ser frequentemente utilizados para complementar o trabalho de pesquisa documental de historiadores e juristas. Esse período culmina com o julgamento de Eichmann em 1961. As testemunhas de guerra falam antes das comissões de inquérito de natureza jurídica ou histórica. A pessoa privada, no testemunho, tende a desaparecer atrás dos fatos, cuja verdade deve ser restaurada. Aqui, o testemunho é codificado, orientado inteiramente para a administração da prova: a irrupção da emoção é considerada um embaraço.

Um acontecimento importante marca essa era. Segundo Wieviorka (1998), no julgamento de Eichmann, em abril de 1961, os testemunhos foram solicitados de uma perspectiva judicial, embora tenham sido transmitidos pelo rádio e pela televisão, o que conferiu enorme publicidade ao evento e certa formatação da condução e das formas narrativas. $\mathrm{O}$ julgamento marcou a primeira exploração estratégica dos depoimentos do Holocausto na esfera política. Os sobreviventes cujos testemunhos não tinham influência direta sobre os atos dos acusados, e que foram cuidadosamente selecionados para representar várias classes sociais e diásporas judaicas, foram chamados a 
testemunhar na tentativa de transmitir uma imagem tangível e concreta do Holocausto ao mundo e à geração israelita mais nova, ou, nas palavras do promotor GideonHausner, "para sobrepor em um fantasma uma dimensão da realidade" (WIEVIORKA, 1998, p. 69-70).

Finalmente, na era da testemunha contemporânea, de acordo com Wieviorka (1998), o testemunho é um verdadeiro imperativo social e não é mais uma necessidade interior. Essa era corresponde ao último quarto do século XX e é caracterizada por um conjunto de diversas produções culturais, de coleções a filmes. No final da década de 1970, seguindo a emoção e a controvérsia que se seguiram nos Estados Unidos, França e Alemanha, a transmissão da série de televisão Holocausto (dirigida por Marvin Chomsky em 1978) apareceu pela primeira vez a ideia de que era necessário colecionar, sob a forma de filmes de vídeo, o testemunho dos sobreviventes (survivors, denominação dada pelos norte-americanos), isto é, de todos os judeus deportados ou não que viveram sob a dominação nazista no Terceiro Reich ou nos países ocupados e que escaparam da morte. Apesar das críticas ferozes dos próprios sobreviventes sobre a mediocridade do exercício de publicização dos testemunhos, a série foi um sucesso. Ela inaugura, segundo Wieviorka (1998), “a era da testemunha”. Uma era de coleta sistemática de testemunhos audiovisuais é iniciada.

Essa nova era culmina com o filme a Lista de Schindler (1993), de Steven Spielberg, e com a Fundação Shoah, fundada por Steven Spielberg em 1994, após o seu trabalho no filme. A Fundação Shoah avançou numa variação de testemunho diferente e mais popular. Animado pelo esforço para coletar tantos testemunhos quanto possível, antes que os sobreviventes morram, afirmando que cada sobrevivente tem uma história única a contar, na Fundação Shoah, o testemunho adquiriu dimensões industriais, produzindo mais de sessenta mil testemunhos de vídeo em mais de trinta línguas, segundo Wieviorka (1998). As entrevistas realizadas pela Fundação em muitas partes diferentes do mundo seguiram um protocolo rigoroso e mostraram um formato semelhante. Eles deveriam culminar em uma mensagem dirigida às próximas gerações, uma cena que os membros da família do sobrevivente foram convidados a participar. Pode-se reconhecer nessa conduta a cena de encerramento da Lista de Schindler, o final feliz para o qual a narração de testemunho foi concebida, a fim de liderar a recuperação e a salvação como seu leitmotiv (WIEVIORKA, 1998). ${ }^{3}$

\footnotetext{
${ }^{3}$ Segundo Wieviorka (1998), o filme Shoah, de Claude Lanzmann (1985) - que é a antítese da série norteamericana -, proclama a irrepresentabilidade do Holocausto e é centrado no testemunho, considerado o
} 
Ao terminar seu filme com um desfile de personagens reais, Spielberg buscava recriar uma continuidade entre o tempo da perseguição e o da memória. Como observa Wieviorka (1998), trata-se de um tipo de testemunho que fala ao coração e não necessariamente à razão. Provoca compaixão, piedade, indignação e, às vezes, revolta, sentimentos perfeitamente honrados, mas, segundo ela, dos quais o historiador só poderia se distanciar, porque toda a verdade individual é e só pode ser parcial e porque o rigor da narrativa histórica não pode ser alcançado sob o signo e a pressão das emoções. Segundo Wieviorka (1998), tanto a fundação quanto o filme representam um trabalho de memórias traumáticas ao estilo de melodrama de Hollywood.

O registro sistemático dos depoimentos dos sobreviventes do Holocausto, mas também das vítimas dos recentes massacres na Bósnia, Ruanda, Kosovo e assim por diante, no final do século XX, é considerado um pré-requisito para o conhecimento dos fatos pelas vítimas, pelos testemunhos delas, base para uma futura narrativa histórica. Exemplificam o que Wiervioka identificou como "a era da testemunha". No entanto, segundo ela (1998), contrariamente a uma opinião bastante difundida, testemunho e história não coincidem, não têm as mesmas funções, mesmo que a abundância de testemunhos e sua onipresença no espaço público confrontem o historiador com problemas tanto antigos quanto novos.

Já para DominickLaCapra (2001), a crítica ao testemunho pode produzir uma adesão ao neopositivismo na história, que reclama um modelo de conhecimento baseado no documento escrito e acredita que toda interpretação é anacrônica. Nesse modelo, a narrativa é um problema (não como um problema de pesquisa); é um empecilho para chegar à verdade pela pretensa verdade implícita na narrativa pessoal. Para LaCapra, deve ser mais objeto de pesquisa a empatia com o relato, as formas narrativas de produzir tal empatia em dado contexto, suas convenções e sistemas de reconhecimento, do que a verificação da verdade do testemunho. A produção da veracidade, antes de efeito de sentido, é um fenômeno cultural, inserido no horizonte cultural de uma sociedade numa época.

Transformado pela adoção de tecnologias de vídeo que possibilitaram registrar os testemunhos à medida que se desenrolava, o processo de testemunho também foi estabelecido como a principal preocupação de um vasto aparelho institucional. $\mathrm{Na}$

único meio capaz de explicar o fenômeno genocida. O uso da testemunha por Claude Lanzmann contribuiu grandemente para a reabilitação de uma palavra pessoal: ele coloca a testemunha e sua história no centro da obra, tecendo, a partir de testemunhos individuais, uma narrativa coletiva. 
inclinação melodramática dos testemunhos contemporâneos do Holocausto e no enquadramento individualizado do testemunho, Amos Goldberg (2009) observou uma tendência normativa. Enquanto a regulamentação do testemunho havia se concentrado anteriormente na avaliação da capacidade do testemunho como prova jurídica, o dispositivo testemunhal contemporâneo procurou regular os modos de se tornar uma testemunha. Concomitantemente, iniciativas especializadas na coleta de testemunhos, museus do Holocausto e projetos educacionais também enquadram a testemunha como uma figura solitária, isolando seu discurso de outros e tornando-o ético e pedagogicamente significativo por seu próprio direito. Por outro lado, como argumenta Lerner (2013), os processos de comunicação online possibilitaram uma reconfiguração das formas de produção, circulação e consumo dos testemunhos em vídeo da Fundação Shoah, particularmente, presentes em vários sites e redes sociais. Se, num primeiro momento, o testemunho em vídeo trouxe um "efeito de vida real" - para usarmos a expressão de Arfuch (2010) -, uma vez que assistimos ao corpo, à voz, à narrativa, enfim, a presença da testemunha como representação audiovisual, o fluxo de informações proporcionado pela internet nos permite acesso a um conjunto diversificado de vídeos, mas também a produção de muitos outros.

A democratização do testemunho e a sua transformação em uma ação que cruza os limites das classes e grupos sociais, mas também dos eventos genocidas, foram reguladas por regimes discursivos que prescrevem, de várias formas, como alguém se torna uma testemunha, o que é um discurso autêntico, o que é sofrimento suficiente para ser digno de reparação ou, ainda, o que é preciso para superar por si. Embora envolvido na intervenção mais pessoal e idiossincrática na esfera pública contemporânea, a pessoa que testemunha também se inscreve em uma tradição codificada que não só exalta o testemunho, mas também estabelece os modos convencionais de realizá-lo e interpretálo. A testemunha contemporânea raramente é a única autora de seu testemunho: sua deposição é moldada por especialistas e instituições que registram, classificam, arquivam, publicam e divulgam testemunhos, mas também - e principalmente - por normas tácitas, modelos estéticos e expectativas políticas que informam a produção do testemunho e sua recepção em determinado contexto. 
A era da testemunha e a cultura da mídia contemporânea

Embora a proeminência do testemunho atualmente seja muitas vezes relacionada ao desenvolvimento das tecnologias de mídia que sustentam e expandem a cultura da autoexposição que tornam as narrativas de primeira pessoa tão atraentes, também é o resultado da transformação do testemunho em parte do processo da produção da subjetividade e da política contemporâneas. Além dos fatores mais aparentes descritos acima, o testemunho deve sua proeminência como uma ferramenta política aos aparelhos interpretativos em que foi incorporada e ao raciocínio ético a que deu origem, que evoluiu conjuntamente com os dilemas de testemunhar e as controvérsias que desencadeou. O testemunho tem sido frequentemente acionado como uma forma de denúncia, de ação política, baseada na experiência pessoal.

A ampliação do testemunho na cultura contemporânea demonstra que a função política do testemunho como narrativa de uma experiência-limite por um sobrevivente se expandiu justamente porque as noções de trauma e de sobrevivência estão se ampliando. O trauma se alargou como categoria e passou a abarcar um conjunto diversificado de eventos, incluindo a separação, o preconceito, o bullying e assim por diante. Essa manifestação do testemunho encontra muita relevância na mídia - em programas de televisão e rádio, revistas e jornais - mas também na internet. Isso, certamente, tem a ver com as mudanças socioculturais do nosso tempo.

Em talk shows é comum a acomodação de temas do trauma em cenários narrativos baseados em um movimento que passa do tormento a um reconfortante final feliz, apresentando a "vítima-sobrevivente" como a protagonista de uma narrativa épica e, por isso, é alguém a quem se concede um estatuto moral superior (ROTHE, 2011, p. 89). Além disso, trata-se de um tropo ao mesmo tempo recorrente e problemático, podendo transformar um conjunto diverso de situações (da violência sexual ao racismo, passando pelo incêndio, o assalto e até mesmo a superstição) como experiências traumáticas importantes na medida em que podem contribuir para o crescimento pessoal. Além da designação extremamente genérica e ampla do trauma, bastante característica do processo de psicologização da sociedade.

O trauma parece ser o único atributo de uma incompatibilidade entre um indivíduo normal e um evento extraordinário. A classificação nosográfica de estresse pós-traumático criou as condições para que o trauma fosse governado por um regime que certifica a autenticidade dos sintomas de angústia, como prescrito pela primeira vez 
no DSM-III (DiagnosticandStatistical Manual of Mental Disorders, de 1980), consagrando o papel de vítima e produzindo uma ética pública psicologizada. Embora o trauma seja visto como uma articulação entre uma cadeia de eventos psíquicos e seus contextos, bem como entre o sujeito e o sentido atribuído posteriormente à situação vivida por conta de um dano emocional desenvolvido, contemporaneamente, observamos uma definição genérica de trauma na terminologia clínica e na linguagem cotidiana, associada a um vasto conjunto de sintomas, situações e de representações prédefinidos. Como um transtorno psicológico que ocorre em resposta a um evento estressante de natureza excepcionalmente ameaçadora, dolorosa ou catastrófica, o trauma vem sendo definido pela duração da situação estressante, pela extensão do acontecimento na vida do afetado, pelas mudanças no humor e a ansiedade, pela sucessão ou multiplicidade de experiências traumáticas, pela falta de preparo para lidar com a situação e pelo desamparo para lidar com os problemas. Desse modo, a expansão da noção e da experiência do trauma faz com que uma diversidade de situações seja definida como traumática, mas o torna um ponto biográfico nodal: a partir dele "os indivíduos estabelecem a narrativa sobre suas próprias vidas" (FASSIN; RECHTMAN, 2009, p. 412), no antes e no depois de experiência desafortunada, mas também sobre o seu durante, sobre o próprio acontecimento traumático.

O trauma se generaliza numa cultura marcada pelo discurso terapêutico e passa a definir uma ordem diversificada de eventos como acidentes, doenças, separações, abusos, violências, discriminação, transtornos psicológicos e assim por diante. Enquanto a felicidade ou a superação é característica de um sujeito ativo e pleno de capacidade de autogestão, o discurso terapêutico na cultura contemporânea produz sujeitos que se sentem em diversas experiências da vida cotidiana (casamento, separação, escola, trabalho, reunião familiar) vulneráveis, frágeis ou em risco de perderem a si mesmos diante de um mundo repleto de adversidades e tormentas (FUREDI, 2004).

Assim, é produzida pelo discurso contemporâneo uma compreensão cada vez mais generalizada da própria vida como uma "disfunção generalizada" (ILLOUZ, 2011, p. 77). Desse modo, há uma ambiguidade nessa positivação de experiências consideradas traumáticas: se, por um lado, produzem a necessidade de transformar o sofrimento com as adversidades no material que será internamente reciclado em prol do autoaprimoramento (ILLOUZ, 2003), por outro, naturaliza ou minimiza experiências drásticas de violência, preconceito, crime, catástrofe, guerra ou adoecimento, uma vez 
que elas serviram para comprovar ou exercitar a capacidade individual de superação. É frequente nesse contexto a valorização do papel de heróis de si mesmo na caracterização das experiências e dos indivíduos por meio das narrativas, caracterização bastante num contexto terapêutico (SACRAMENTO, 2016; SACRAMENTO; FRUMENTO, 2015; SACRAMENTO; RAMOS, 2018). O que passa a ser importante é menos mostrar o sofrimento vivido do que como os indivíduos superar os problemas.

É muito comum nos estudos sobre narrativas autobiográficas que expõem a intimidade na mídia classificar tais manifestações como sendo prioritariamente confessionais. Ao analisar os depoimentos televisivos de celebridades sobre sofrimentos íntimos, é frequente a inspiração na obra de Michel Foucault (1988) sobre a confissão como uma agência de verdade e de poder na sociedade ocidental. White (1992, p. 186) afirma que "a confissão e o discurso terapêutico se tornam estratégias narrativas centrais da televisão nos Estados Unidos". Os problemas e as suas soluções estão narrativizados em termos de relações confessionais. Como afirma a autora (1992), a autoidentidade e o reconhecimento social dependem de participação no processo de confissão mediada.

Examinando a história da confissão, Michel Foucault (1988, p. 140) argumenta que a confissão é uma tecnologia usada em uma série de práticas. A confissão espalhou seus efeitos em toda parte. Ela desempenha um papel na justiça, medicina, educação, relações familiares e as relações de amor, nos assuntos mais comuns da vida. Nas palavras do autor, o homem ocidental tornou-se um animal confessor. É a partir disso que muitos estudos sobre talk shows enfatizam a confissão como figura narrativa fundamental.

Por sua vez, Jane Shattuc (1997) argumenta que, pelo contrário, há uma configuração testemunhal do discurso em tais programas em relação às práticas emancipatórias do feminino e suas relações com as práticas religiosas cristãs, sobretudo, protestantes:

Como os shows são arenas públicas que não evocam a intimidade e a profundidade da terapia ou até mesmo conscientização dos grupos? Mas por causa de seus laços com a ideologia social, tais como o feminismo, a sua estrutura discursiva envolve testemunhos em vez de confissões. O testemunho tem uma longa história na América, do fundamentalismo e da mídia evangélicos. E foi revigorado no movimento de doze passos, um modelo secular de testemunhar. $O$ sentido religioso original da prática significa que o testemunho público dado por testemunhas tinha o poder salvador de Cristo. Dentro do evangelismo o ato de levantar-se e falar da própria experiência religiosa é uma obrigação social (SHATTUC, 1997, p. 130). 
Embora narrar uma história dolorosa claramente não é uma terapia, como explica a autora, o engajamento do convidado especialista/terapeuta na narrativa é apenas uma representação da prática terapêutica. Nesse sentido, as reflexões de Shattuc (1997) sobre o testemunho em programas de televisão são muito pertinentes. A tradição de evangelismo é o que dá forma e significado para os depoimentos ouvidos no programa de Oprah Winfrey ou no de Fátima Bernardes, por exemplo, ainda que de modo secular (SACRAMENTO, 2017). Testemunhar, assim, instaura-se como tendo poderes de cura, de autorrenovação e de autorregeneração. A história das práticas confessionais e testemunhais religiosas é longa e complexa e não será discutida aqui. Todavia, concordamos com Shattuc (1997) quando diz que há ligações entre a prática de testemunho na igreja neopentecostal e a presença do discurso terapêutico na vida cotidiana, no modo como as pessoas narram em diferentes mídias experiências de sofrimento. Os processos de confissão e testemunho oferecem os meios de expressar um eu que tem poderes. É importante notar a enorme recorrência de termos associados a noções de autorrealização e autoestima que marcam o movimento de passagem da noção de vítima à de sobrevivente.

Além disso, acredito, assim como Paulo Vaz (2014, p. 35), que há uma substituição da confissão pelo testemunho como discurso autobiográfico dominante , porque os testemunhos "se dão no espaçopúblico e o sujeito de enunciado não é o indivíduo como agente - alguém que faz ou deseja - mas, sim, como vítima, com o relato demorando -se na descrição de sua experi ência de sofrimento" . Além disso , "a verdade desse discurso não se fundamenta mais no perito e no discurso científico , mas, sim, na exibição do sofrimento e da sinceridade" por aquele que viveu o que narra (VAZ, 2014, p. 35). São predominantemente testemunhais as narrativas autobiográficas de celebridades e indivíduos comuns na cultura contemporânea. Elas relatam como tais sujeitos conquistaram a superação de experiências traumáticas.

Seguindo essa perspectiva, é preciso considerar que o testemunho conta com um endereçamento. O testemunho se dá no espaço público, já a confissão se restringe ao espaço privado. Isso se dá "em parte pelo fato de a Internet permitir que indivíduos quaisquer enviem mensagens à distância para muitos, torna-se perceptível uma espécie de explosão do discurso autobiográfico na cultura contemporânea", mas também em razão da dinâmica terapêutica do testemunho: "A ida ao espaço público e não o segredo" (VAZ; SANTOS; ANDRADE, 2014, p. 02). 
Gostaria de propor aqui algumas respostas para a valorização do testemunho na cultura contemporânea. A primeira dela diz respeita ao regime de visibilidade contemporâneo na reconfiguração das formas de produção de subjetividade e de sociabilidade. Os últimos anos do século XX foram marcados por relacionamentos entre as esferas do público e do privado tão intensos que a intimidade assume e se configura a partir da visibilidade midiática. É comum pontuar que o significado do que é de caráter públicose alterou num mundo permeado por tecnologias de comunicação e difusão de informações em rede, onde os indivíduos podem interagir com outros e observar pessoas e eventos sem sequer estarem no mesmo ambiente espaço-temporal. As práticas de sociabilidade promovidas pela internet permitiram formas de publicação de si, baseadas numa nova organização subjetiva: "Uma passagem do mundo abissal dos sentimentos" para uma "preeminência da sensorialidade e da visibilidade instantânea" (SIBILIA, 2008, p. 04).

Numa era em que o exibicionismo tem forte presença entre as características sociais, há enorme valorização da visibilidade, do ser visto, do ser notado, do ser curtido, comentado, compartilhado. Não basta aparecer, é preciso alcançar um destaque entre as pessoas. Num contexto de promoção da crença de que qualquer um pode se tornar um personagem atraente nas telas e se tornar célebre, as mídias online se popularizam. As pessoas cotidianamente fazem da "sua vida um espetáculo destinado a milhões de olhares curiosos de todo o planeta" (SIBILIA, 2008, p. 55). Há, portanto, uma necessidade cada vez maior de se exibir e compartilhar com os outros a vida, a interioridade, o particular, a intimidade, em oposição ao invisível, o ocultado, o secreto e o proibido: "Tudo aquilo que antes concernia à pudica intimidade pessoal tem se 'evadido' do antigo espaço privado, transbordando seus limites, para invadir aquela esfera que antes se considerava pública" (SIBILIA, 2008, p. 53).

A moral contemporânea do espetáculo envolve uma mudança de ênfase na produção da subjetividade: da satisfação sentimental à sensorial, pela qual se estabelece "uma nova educação dos sentidos, uma nova percepção da morfologia e das funções corporais que tornou o bem-estar sensorial um sério competidor do bem-estar sentimental" (FREIRE COSTA, 2005, p. 166). Sendo assim, há uma drástica mudança moral: da moral dos sentimentos para a moral do espetáculo. A moral dos sentimentos constituiu alguns dos traços mais marcantes da modernidade, especialmente no século XIX: “A construção de um ideal de subjetividade caracterizado pela capacidade de 
autoconsciência, lucidez, cálculo, equilíbrio, controle e objetividade, mas também na confiança no mundo interior, no universo de sentimentos e na capacidade de se expressar no mundo exterior" (FREIRE COSTA, 2005, p. 167).

Essa argumentação implicitamente concorda com as teses de Guy Debord (1997) sobre a sociedade do espetáculo, na qual a imagem como aparência é feita inerência, o que acaba prescrevendo como forma de viver a imitação do que se dá nos signos e narrativas midiáticos. A crítica de Debord também serve de inspiração para Paula Sibilia (2008). Numa era de intimidade performatizada midiaticamente como exterioridade pública, a produção da subjetividade e da identidade estão inexoravelmente associada às tecnologias de comunicação, que permitem a superexposição da vida íntima como espetáculo - o show do eu, como argumenta a autora. Para ela, especialmente nos ambientes online, com o intuito de construir referenciais identitários, a utilização de imagens junto a outros artifícios discursivos produz uma gama de sentidos que corroboram uma tendência da contemporaneidade : a necessidade de "atualização permanente - e sempre recente - das informações, por meio de fragmentos de conteúdo adicionados a todo o momento" $\quad$ (SIBILIA, 2008, p. 116). Em um espaço no qual o indivíduo tem o poder de administrar as suas interações permitindo ou não , com mais facilidade , a exposição do juízo alheio sobre si , é ainda mais perceptível o caráter "alterdirigido" da subjetivid ade, isto é, "o que se é deve ser visto - e cada um é aquilo que mostra de si” (SIBILIA, 2008, p. 235).

O fenômeno da visibilidade em torno da realidade banal da vida privada de celebridades não se restringe apenas à mídia massiva : televisão, revistas e jornais . A espetacularização da intimidade de celebridades agora também é expressa de forma voluntária, ganhando destaque no meio digital, por famosos ou não. As redes sociais online, mas também os blogs e canais do YouTube conformam o espaçocontemporâneo de evasão da privacidade. As práticas de exposição da intimidade na Internet constituem uma visibilidade expandida, que subverte os limites entre o público e o privado e renova o interesse pela relação com o olhar do outro e pela $\quad$ s formas de espetacularização aí implicadas.

Ao espetáculo das celebridades se acrescenta o espetáculo dos anônimos . Há aí um retorno do foco de visibilidade sobre o indivíduo comum . Telas de TV, de computador e de smartphones constituem um campo de visibilidade para o indivíduo comum. Este deixa de ser apenas espectador da vida alheia e se torna também ator de 
sua própria vida, no que ela tem de mais corriqueiro e ordinário . O que torna esse indivíduo digno de visibilidade e interesse não é t anto a sua existência banal e cotidiana, mas o fato mesmo de expor o que se costumava manter no âmbito privado e íntimo Vemos na atual exposição da vida íntima e privada um paroxismo da cultura do espetáculo. A espetacularização não apenas penetra nos espaços privados e cotidianos na forma de uma realidade espetacular pela mídia , mas torna a legitimação da existênciaíntima e cotidiana atrelada à sua própriaespetacularização . Ela se torna, assim, vetor de socialização, identificação e subjetivação.

Nesse contexto, é que acreditamos que o testemunho se torna uma das formas mais presentes de narrativa autobiográfica. Sua característica pública está plenamente associada ao imperativo de visibilidade. Segundo Arfuch (2010), a expressão da própria subjetividade em forma de testemunho, tanto na mídia quanto na política, tem uma âncora prioritária no estabelecimento da memória pública como um dever ético em sociedades contemporâneas e, portanto, na valorização do testemunho, nas suas formas mais diversas, como forma de explicar a experiência do passado traumático. Além do individualismo e do espetáculo, segundo ela, há um valor testemunhal em jogo. Afinal, cada narrativa autobiográfica também é coletiva, fala de famílias, grupos, gerações, de identidades, de grupos sociais e, em certo sentido, da humanidade. Mas, ao mesmo tempo, os gêneros íntimos estão cada vez mais considerando a experiência do pequeno, do cotidiano, como uma âncora para a intimidade como segurança ontológica e como forma necessária de identificação e reconhecimento.

Outra possível resposta para a atual valorização do testemunho, desta vez, a curiosidade, é uma condição paradoxal, à luz das distinções modernas entre o público e o privado, que torna a intimidade algo a ser contado, bem como o segredo a ser revelado. Mas o que se busca nessas histórias não é tanto a verdade referencial - a adaptação aos fatos -, mas, sim, a autenticidade da voz que conta, a sua expressividade, suas estratégias narrativas, sua presença, como garantia de uma existência real (ARFUCH, 2010). No entanto, em vez de "sua própria experiência", essa autenticidade é em si um valor: quem diz "isso aconteceu comigo" coloca o corpo no discurso, oferecendo ao público uma prova viva: a prova é a própria vida. Essa identificação com o outro, de um indivíduo com outro, de uma história com outra, busca compensar o que nos falta, considerando a perspectiva psicanalítica. A identificação não se dá necessariamente com a vida glamorosa - feliz, rica e famosa, vencedoras notáveis e 
bem-sucedidas -, mas também - e diríamos, até, principalmente - com a fraqueza, o infortúnio, o sofrimento (SACRAMENTO; RAMOS, 2018. Isso, no entanto, não se dá apenas pela falta, mas especialmente pela proximidade, pelo reconhecimento no outro de si mesmo, de uma vida semelhante problemática e infeliz, algo que vem sendo frequentemente mais considerado como efetivamente a "vida real" ou o "mais real da vida" (LITTER, 2004, p. 18).

\section{Considerações finais}

O espaço biográfico contemporâneo é certamente marcado pela implantação interminável de tecnologias de comunicação: multiplicidade de formas, gêneros, estilos e mídias. Nesse contexto, é possível observar uma enorme reconfiguração da subjetividade contemporânea, associada ao discurso terapêutico e à moral do espetáculo.É, sem dúvida, a disseminação de formas de narrativas autobiográficas que contribui para reforçar valores de autenticidade, autoafirmação e exclusividade diante da uniformidade, da impessoalidade e do anonimato das nossas sociedades. Esse registro em primeira pessoa valoriza enormemente a testemunha como uma expressão da experiência, individual e coletivamente.

O espaço biográfico altera decisivamente, como argumentei, as esferas clássicas do público e do privado para delinear um tipo de intimidade pública, tanto em seu caráter modelo de conduta social quanto na sua forma de implantação de uma subjetividade alterdirigida. A importância testemunhal e terapêtica da narrativa de experiências traumáticas, tanto em termos de histórias familiares como de violência política e crimes contra a humanidade, a relevância ética das histórias de vida na formação de novas identidades, sexuais, de gênero ou em situações cotidianas de conflitos se conectam com cultura contemporânea da autoexposição.

O que certamente está mudando é o valor do testemunho. Há cada vez mais uma exigência para apresentar a si mesmo não apenas em constante recuperação, mas na transformação da sobrevivência num princípio normativo para a subjetividade contemporânea. Ou seja, enquanto a ideia de recuperação contínua (de nunca estarmos recuperados o suficiente em relação aos eventos de sofrimento, mas de termos de estar em tratamento e recuperação permanentes) reforça a sensação de vulnerabilidade (de viver constantes ameaças à segurança psíquico-ontológica pela própria experiência da vida), há ainda uma outra característica subjetiva socialmente valorizada: a capacidade 
de sobreviver aos infortúnios. Os sobreviventes já tiveram em algum momento suas existências marcadas pela extrema violência, em eventos-limite da experiência humana, como catástrofes, genocídios, extrema miséria, guerras e atentados terroristas. Há, contemporaneamente, uma nova significação da sobrevivência: a sobrevivência como resiliência e o sobrevivente como resiliente (SACRAMENTO, 2017).

Referências

ARFUCH, Leonor. O espaço biográfico: dilemas da subjetividade contemporânea. Rio de Janeiro: Ed. UERJ, 2010

CHAUVEAU, Agnès; TÉTART, Philippe. Questões para a história do presente. In: (Org.). Questões para a história do presente. Bauru: EDUSC, 1999, p. 7-38.

DEBORD, Guy. A sociedade do espetáculo. Rio de Janeiro: Contraponto, 1997.

FASSIN, Didier; RECHTMAN, Richard. The empire of trauma: an inquiry into the condition of victimhood. Princeton: Princeton University Press, 2009.

FOUCAULT, Michel. História da Sexualidade I: a vontade de saber. Rio de Janeiro: Forense Universitária, 1988.

FREIRE COSTA, Jurandir. O vestígio e a aura. Rio de Janeiro: Garamond, 2005.

FUREDI, Frank. Therapy culture. Londres: Routledge, 2004.

GOLDBERG, Amos. The victim's voice and melodramatic aesthetics in history. History and Theory: Studies in Philosophy of History, v. 48, n. 3, p. 220-237, 2009.

ILLOUZ, Eva. O amor nos tempos do capitalismo. Rio de Janeiro: Jorge Zahar, 2011.

Oprah Winfrey and the glamour of misery: an essay in popular culture. New York: Columbia University Press, 2003.

LACAPRA, Dominik. Writing history, writing trauma. Baltimore, Maryland: The Johns Hopkins University Press, 2001.

LITTLER, Jo. Making fame ordinary: intimacy, reflexivity, and "keeping it real". Mediactive, n. 2, p. 8-25, 2004.

LERNER, Katia. Memórias da dor: coleções e narrativas sobre o Holocausto. Brasília: IBRAM, 2013.

RIOUX, Jean-Pierre. Pode-se fazer uma história do presente ? In: CHAUVEAU, Agnès; TÉTART, Philippe (Org.). Questões para a história do presente . Bauru: EDUSC, 1999, p. 39-50. 
ROTHE, Anne. Popular trauma culture: selling the pain of others in the mass media. Londres: RutgersUniversity Press, 2011.

SACRAMENTO, Igor. "A autoestima é muito importante": a retórica da salvação pessoal nos relatos de celebridades sobre o bullying. Lumina (UFJF), Juiz de Fora, v.11, n. 3, p. 55-74, set./dez. 2017. Disponível em:

<https://lumina.ufjf.emnuvens.com.br/lumina/article/viewFile/590/528>. Acesso em: 15 jun. 2018.

O espetáculo do trauma: narrativas testemunhais de celebridades sobre o bullying num programa de TV. Contracampo (UFF), Niteroi, v. 35, n. 2, p. 157-182, maio/ago. 2016.2 Disponível em: <http://www.contracampo.uff.br/index.php/revista/article/view/940>. Acesso em: 15 jun. 2018.

; FRUMENTO, Eduardo. O câncer nas biografias sobre José Alencar: a construção de um ethos heroico. Revista Fronteiras (Online), São Leopoldo, RS, v. 17, n. 3, p. 374-385, set./dez. 2015. Disponível em: <http://revistas.unisinos.br/index.php/fronteiras/article/view/fem.2015.173.11>. Acesso em:12 abr. 2018.

; RAMOS, Douglas. Documentando a superação: Demi Lovato - Stay Strong e o discurso terapêutico contemporâneo. Verso e Reverso, São Leopoldo (RS), v. 32, n. 79, p. 59-72, jan./abr. 2018. Disponível em: <http://revistas.unisinos.br/index.php/versoereverso/article/view/ver.2018.32.79.06>.

Acessoem: 20 maio 2018.

SHATTUC, Janet. The talking cure: TV talk shows and women. New York: Routledge, 1997.

SIBILIA, Paula. O show do eu: a intimidade como espetáculo. Rio de Janeiro: Nova Fronteira, 2008.

VAZ, Paulo. Compaixão, moderna e atual. In: FREIRE FILHO, João; COELHO, Maria das Graças Pinto (Org.). Jornalismo, cultura e sociedade: visões do Brasil contemporâneo. Porto Alegre: Sulina, 2014, p. 73-98.

VAZ, Paulo; SANTOS, Amanda; ANDRADE, Pedro Henrique. Testemunho e subjetividade contemporânea: narrativas de vítimas de estupro e a construção social da inocência. Lumina, Juiz de Fora, v. 8, n. 2, p. 1-33, dez. 2014. Disponível em: $<$ https://lumina.ufjf.emnuvens.com.br/lumina/article/view/407>. Acessoem: 10 mar. 2018.

WHITE, Mimi. Tele-advising: therapeutic discourse in American television. Chapel Hill: University of North Carolina Press, 1992.

WIEVIORKA, Annette. L'ère du témoin. Paris: HachetteLittératures, 1998.

Submetido em: 15.05 .2018

Aprovadoem: 23.06.2018 